\title{
Variable Speed Drives as Elements of IoTSP for Industry 4.0
}

\author{
Naděžda Pavelková \\ ABB Drives and Motors, Prague, Czech Republic, e-mail: nadezda.pavelkova@cz.abb.com
}

\begin{abstract}
News from variable speed drives remote monitoring, parametrization, diagnostics; tuning and maintenance. Variable speed drives as a part of Industry4.0 and IoTSP (Internet of Things, Services and People). Vision of integrated industry. Intelligent use of data to optimize industry, utility and infrastructure operation and increase productivity and flexibility.
\end{abstract}

Keywords - Industry 4.0, IoTSP, monitoring, parametrization, tuning and diagnostics, $A B B$ Ability ${ }^{T M}$ Smart Sensor, Drivebase, Remote Condition Monitoring, Drivetune, frequency converters, motors.

\section{INDUSTRY 4.0 AND IOTSP}

\section{A. Industry 4.0}

What to conceive of a term Industry 4.0 everybody is talking about? For several years already, many developed countries have been dealing with the outset of the Fourth Industrial Revolution, which fundamentally alters the nature of industry, energy, trade, logistics and other parts of the economy and society as a whole. The main idea of this completely new philosophy is the systemic use, integration and interconnection of various technologies in the consideration of their lasting, very rapid development and the need to prepare - for the industrial production and non-production sphere - conditions that will enable the implementation of the new (so called fourth) industrial revolution. The first, second and third industrial revolutions were marked by the major events that follow:

- Industry 1.0 - Thomas Newcomen designed and constructed the first serviceable steam engine in 1712 .

- Industry 2.0 - The first belt conveyor was constructed in Cincinnati (USA) in 1870.

- Industry 3.0 - Richard Morley and Odo J. Struger designed the programmable logic controller, and Morley introduced the sequential logic controller based on semiconductors in 1969.

Industry 4.0 also introduces terms such as intelligent production plant, cyber-physical systems and internet of things.

\section{B. IoTSP}

IoTSP is another abbreviation that relates to this topic. Things or devices are equipped with sensors and are connected using mobile communication devices or clouds. People take over the positions of managers, decisionmakers and programmers. A system of services is thus generated, as well as applications and algorithms that are integrated dynamically. Extensive data exchange takes place and data objects actively support the manufacturing process, design, optimization, service and predictive maintenance. Using the information technology, for example, multiple businesses or locations can be integrated into one intelligent manufacturing plant, the main strengths of which are safety, efficiency, targeted process planning, low unit cost, energy cost reduction, and resource management. The final "smart product" is then equipped with a digital memory with information about parts, status, etc. - for example using the list of materials it can be appropriately disposed of at the end of its life. By interconnecting all levels of the value-added chain, all relevant information is available in real-time. This allows better managerial decisions, synergies and greater efficiency. However, this transparency needs to be protected through proprietary security and encryption procedures.

\section{VARIABLE SPEED DRIVES AS A PART OF IOTSP}

\section{A. Modernization of Production Requires also Modern Approach to Service}

If the current form of industry has any distinctive attribute, then it is a change. And this change has been occurring in all spheres - not only in production, where mass production of millions of identical products has been slowly being replaced by tailor-made production complying with the customers' needs, but also in service that has started replacing scheduled maintenance by a predictive and preventive one.

The range of service changes (both in drive service and in service in general) is much broader - not only the way, but also the length and nature of the service performed have been changing. In essence, the entire philosophy of the service changes. The long-used concept of the fixedschedule maintenance and service interventions has been disappearing and being superseded by a predictive one, the purpose of which is to prevent the failures. It can therefore be expected that in the final phase, the service will be more of a consultation and diagnostic activity than of actual service interventions in plant.

It is also clear that the service will increasingly use intelligent devices (such as the so-called smart sensors). Thanks to the increasing digitization, connectivity and ability to communicate effectively will be maximized and the so-called 3P approach (Prediction - Prevention Proactivity) will be adopted. These intelligent devices will provide (and have been already increasingly providing) 
automated collection of information about the operating parameters of the monitored devices (variable speed drives, electric motors, etc.) and enable proactive monitoring of these devices. Based on the correct analysis of data obtained, a possible failure state can be predicted and adequately addressed before the malfunction really occurs - i.e. preventively (see Fig. 1).

The benefits of such a service are clear - longer service life, lower probability of unplanned outages, increased production plant efficiency, and significant reduction in potential security risks. Figures 2 to 5 give some statistics about the total failure rate versus age; winding failure rate depends on voltage, on pole number and on number of motor starts per day.

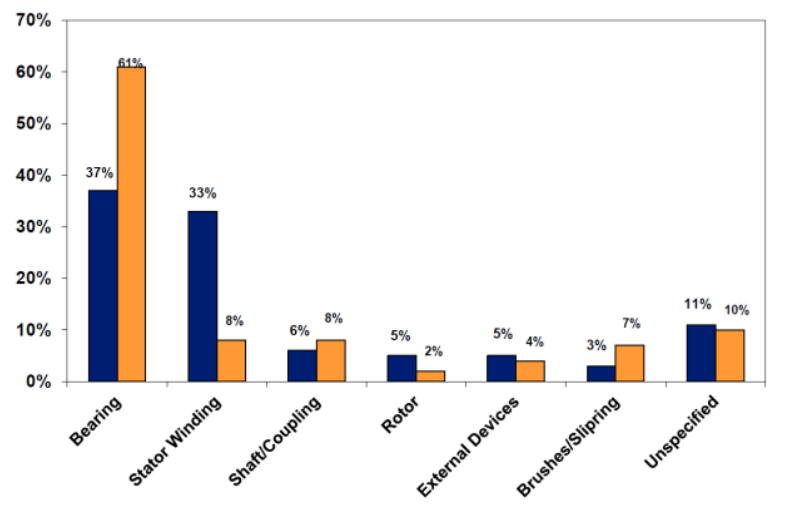

Fig. 1. Failure state comparison. Blue = really occurred malfunction within normal operation. Orange $=$ detected failures with preventive maintenance and operation diagnostic.

Total Failure Rate Vs Age

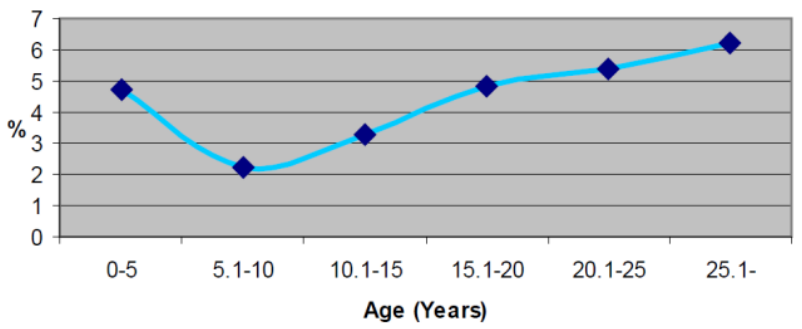

Fig. 2. Total failure rate versus motor age.

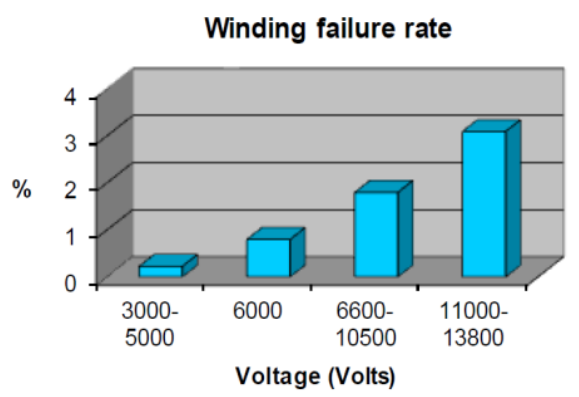

Fig. 3. Winding failure rate versus motor voltage.

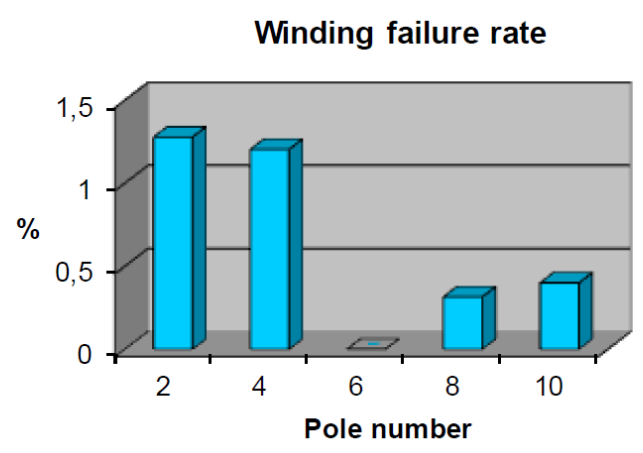

Fig. 4. Winding failure rate versus motor pole number.

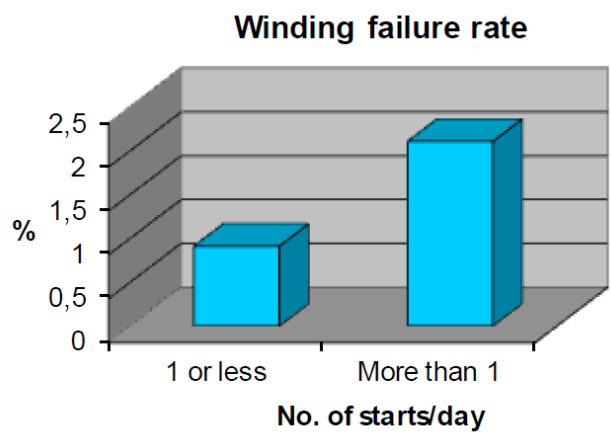

Fig. 5. Winding failure rate versus number of motor starts per day.

\section{B. Remote Diagnostics}

It has becoming a norm that the state-of-the-art technologies are used for monitoring and diagnostics, utilizing the undisputed benefits of remote data transfer. In the case of electric motors, vibration, temperature, condition of rotors / stators, bearings, voltage and current data are most frequently monitored and then sent via secured network to a remote monitoring center. Based on the analysis performed in the center the experts are able to propose appropriate solutions (preventive maintenance, service according to the current state of the motor or replacement, etc.). Since the monitoring and diagnostics are provided in a non-stop mode, the center experts can analyze trends and patterns of the motor behavior and then identify possible fault models. Valuable is also the availability of current and historical data on the operation and behavior of the monitored devices.

\section{1) $L E A P$}

ABB has developed a unique analytical tool for identifying, characterizing and quantifying failures that can occur within insulation systems. The tool is called LEAP - it is an abbreviation of the Lifetime Expectancy Analysis Program. It is a diagnostic tool for assessing the condition and state of the electric machine stator winding insulation from $3 \mathrm{kV}$. The principle of measurement using LEAP is based on the knowledge of the occurrence of failures in the insulation system, their measurement and early detection. For the measurement itself, a set of several measurement methods is used that provide a comprehensive view of individual parts of the insulation system. Thanks to these data $\mathrm{ABB}$ specialists are able to determine the current state of the machine/motor. 
The individual measurement methods include the Polarization - Depolarization Current Analysis (PDCA) analysis, during which time recording of absorption and leakage characteristics is made for a clearly defined time (Fig. 6).

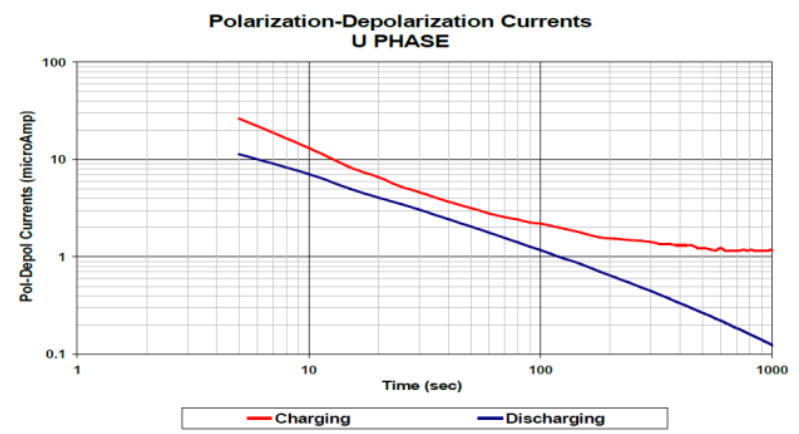

Fig. 6. Polarization-depolarization currents versus time.

These characteristics are among the values that show the degree of contamination of the insulation system and its integrity (damage to some layers of insulation, etc.). The values of partial discharge occurring in the measured insulation system at a certain high voltage level represent another important parameter. During PDCA a DC step voltage of $2500 \mathrm{~V}$ is applied to the winding(s) using a highly regulated electronic power supply with a stability of $<1 \mathrm{~V} / \mathrm{sec}$. The voltage is maintained for a period of not less than 1000 seconds. The current flowing through the insulation is monitored during the charging period.

After all the relevant data are obtained, the windings are discharged through a micro ammeter. The discharge currents are monitored after the initial winding capacitance discharge ( $<5$ secs), over a total time period that is not less than the charging time period.

The measured data indicate the apparent charge generated in the individual elements of the insulation system, but also the corona effect in the electric machine stator cavity. The method of the partial discharge measurement usually reveals the occurrence of an unexpected failure in the insulation system, i.e. the breakthrough of any of the phase voltages to the electric machine frame.

Another very important measured value is $\tan \delta-$ the angle that characterizes the active polarization losses in the insulation (Fig. 7).

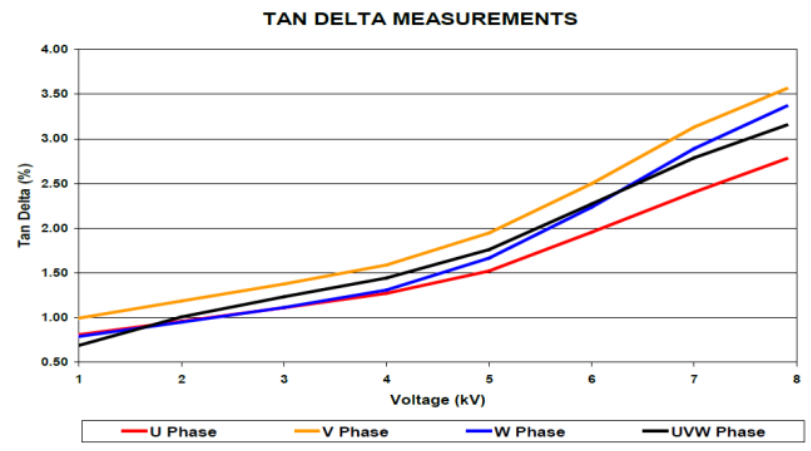

Fig. 7. Tan $\delta$ measurements versus voltage.
With an increasing dissipation factor, insulation becomes more heated and ages faster. This parameter gives an idea of the overall insulation state and its size helps to indicate whether the insulation system is aged or damp. Capacitance and $\tan \delta$ measurements will be performed using a transformer ratio arm bridge. The measurements will be performed at increments that will not exceed $0.2 \mathrm{VL}$. The maximum test voltage will be $(1 / \sqrt{3}) \cdot V L \mathrm{kV}$ r.m.s.

The $\tan \delta$ and capacitance measurements vary with voltage even in the absence of partial discharges, and one of the most obvious reasons for such behavior is the presence of a non-linear field stress grading system at the slot ends. Other reasons are the space charge/interfacial polarization due to contamination, electrostatic forces on delaminated insulation, increased ionic mobility due to aging, surface partial discharges, etc. It is evident that both the voltage supply across the insulation and the current passing through the insulation contain harmonics, which cause an increase or decrease in the measured $\tan \delta$ and capacitance values. Thus, it becomes necessary to understand this time varying effect of the insulation admittance on the measured capacitance and $\tan \delta$.

Non-linear analysis provides a detailed understanding of such non-linear behavior, and thereby supplements the $\tan \delta$ analysis. The analysis provides an additional insight into the aging of the insulation.

The test is performed by applying a known voltage across the insulation, and monitoring the voltage and current flowing through the insulation by capturing several voltage and current waveform cycles on a digital storage oscilloscope. The insulation is tested at a predetermined voltage levels up to a maximum of $(1 / \sqrt{ } 3) \cdot V L$ r.m.s. The instantaneous admittance of the insulation is calculated and the admittance patterns analyzed for specific harmonic patterns.

ABB LEAP Standard service tests the motor/generator during a stoppage to estimate its remaining life in terms of operating hours with an $80 \%$ confidence level (Fig. 8).

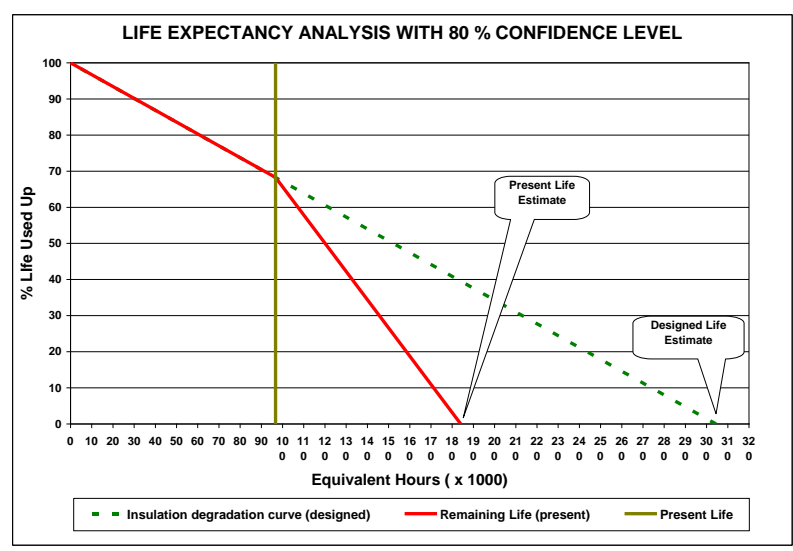

Fig. 8. Life expectancy analysis with $80 \%$ confidence level.

The LEAP method includes:

- data collection,

- data analysis,

- stress calculation,

- lifetime estimation \& condition based maintenance. 
Though use of individual measurement methods does not represent any major breakthrough in the insulation systems diagnostics, the use of results of extensive amount of tested electric motors in the $\mathrm{ABB}$ research and development center combined with the vast experience of experts form a unique approach to the insulation system maintenance.

The outcome of individual processes and special procedures applied both during the data collection and analysis has a form of a final report that provides the customer with information about:

- Contamination of the stator winding (increases stresses and reduces the lifetime).

- Aging of the insulation system, aging of resin, delamination.

- Status of the stress grading system.

- Status of the corona protection system insulation in the stator slot area.

- PD activity in other parts of the stator (e.g. winding overhang).

- Remaining lifetime based on information provided by the customer in combination with the measurements conducted.

- Recommendations for maintenance or other action like rewinding/replacement and recommended time for the next inspection based on the operating information provided.

Figure 9 illustrates the diagnostics of the HV motors and generators using LEAP in the Ostrava service center. The diagnosed motor is a NXR motor with several interesting new features. Figure 10 illustrates the summary LEAP report.

\section{2) MACHsenseP and MACHsenseR}

High-voltage motors and generators can be diagnosed also using the MACHsenseP and MACHsenseR tools. The ABB MACHsense uses an innovative method that combines the measurement of vibration, shaft speed and electrical signals (from the motor) to identify and quantify motor, gearbox and load failures. The MACHsenseP version requires a technician that performs measurement on-site. The main benefits are: a comprehensive approach to monitoring of the condition of the entire shaft chain containing the motor, gearbox and load, the use of several sensors (vibration, current, voltage) with integrated analysis for reporting and early warning of emerging defects providing enough time for maintenance.

The MACHsenseR version transmits the data remotely and the motor is therefore under the permanent supervision of the ABB service technician. The process uses a data analysis unit that is installed near the motor. Sensors located on the motor scan data (four channels for vibrations and five channels for temperature) and send them to the processing unit. For installation, the portable MACHsenseP monitoring device is used and the limit values are set according to the specific operation and load and these are then continuously evaluated. Data are sent over the GPRS or $3 \mathrm{G}$ mobile network, the internet can also be used. Authorized users can connect to the server where the data are stored to view graphs with the time curves, recorded vibrations, temperatures, spectrography, loads, and start counts.

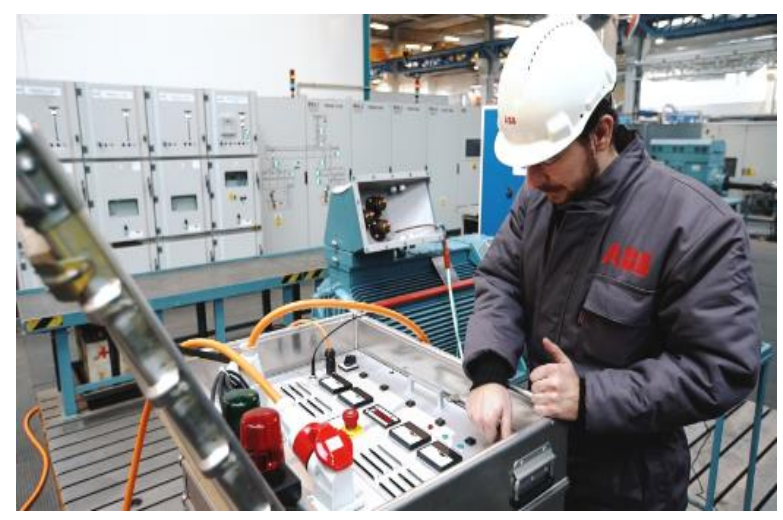

Fig. 9. HV motor and generator diagnostics using ABB LEAP tool.

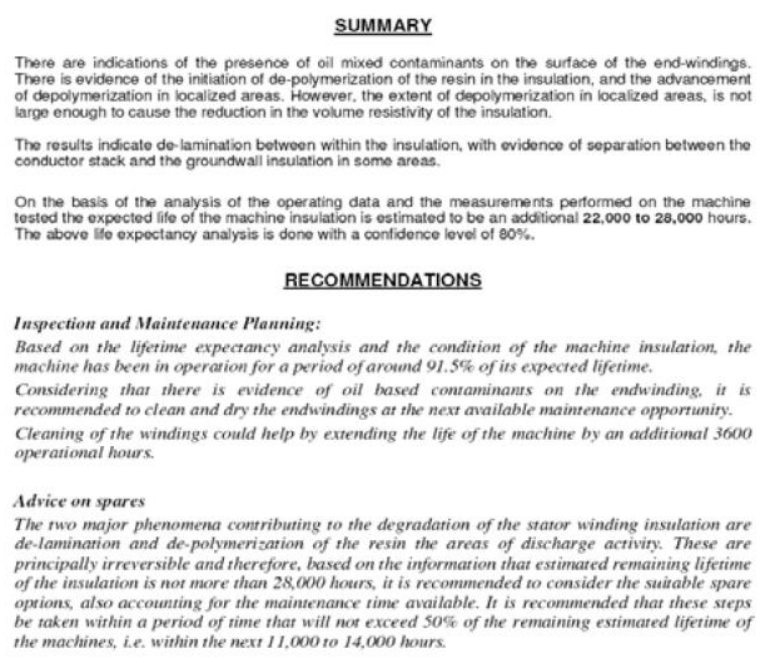

Fig. 10. Summary LEAP report example.

\section{3) ABB Ability ${ }^{T M}$ Smart Sensor for low voltage motors}

The LEAP, MACHsenseP tools are "off line tools" and the MachSenseR is an "on line" tool for permanent HV machine diagnostics. All of them have been developed and used many years ago when Industry 4.0 wasn't defined. ABB's know-how and historical experience with measuring, data collecting and analysing, described before, could be used for low voltage motors also now.

The ABB AbilityTM Smart Sensor (see Fig. 11) is another interesting element enabling the low voltage motor to become an IoSTP element and digitally connected within the frames of Industry 4.0. It is an example of a modern smart device designed to remotely monitor the state of low voltage motors. This new product that $\mathrm{ABB}$ introduced to the professional audience at this year Amper 2017 trade fair (where it was awarded the Golden Amper 2017), measures and transmits - via Bluetooth - essential information about the overall state of the electric motor (for example vibration, temperature and other parameters) to the smartphone. A sensor helps to reduce downtime, extends lifetime, and can contribute to reducing power consumption at the same time. 


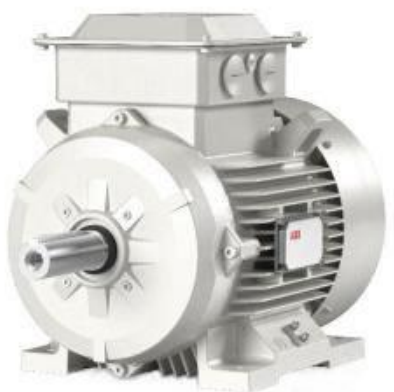

Fig. 11. Electric motor with installed ABB Ability Smart Sensor.

This sensor can be applied to almost any low voltage motor, whether new or already in use, of IEC sizes 140 $450 \mathrm{~mm}$. It is often compared to a fitness bracelet used in sport. It does not require any additional wiring, as it is attached between the ribs of conventional induction motors (all necessary sensors are built in, including the battery power supply). It directly measures the vibrations in three axes and the temperature. Other variables, such as load, bearing condition, revolutions, number of starts, operation hours, etc., are measured indirectly by other sensors.

The connection with motor is done via Bluetooth using mobile phones or tablets. It is thus very easy for the service technicians to diagnose motor status and trends during regular inspections. Another option is to send these data to ABB cloud to be analyzed there using special SW. The results of the analysis will be presented in a form of warnings/alerts and messages (Fig. 12 to 15 ).

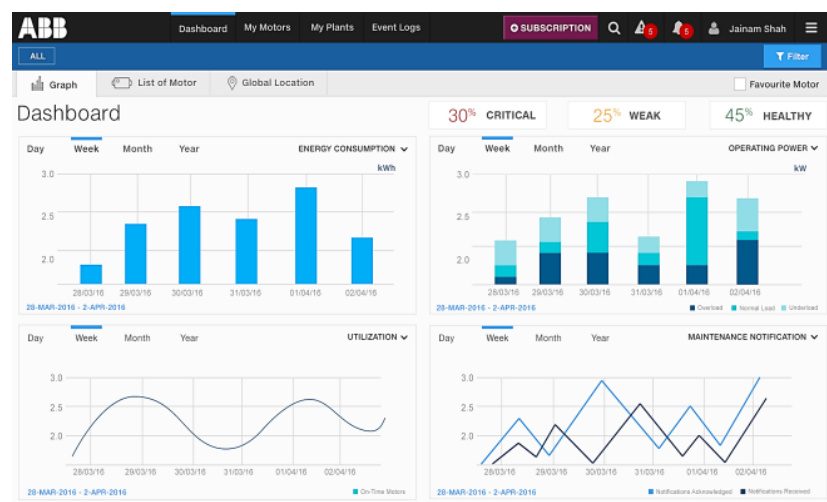

Fig. 12. The example of values recorded by Smart Sensor.

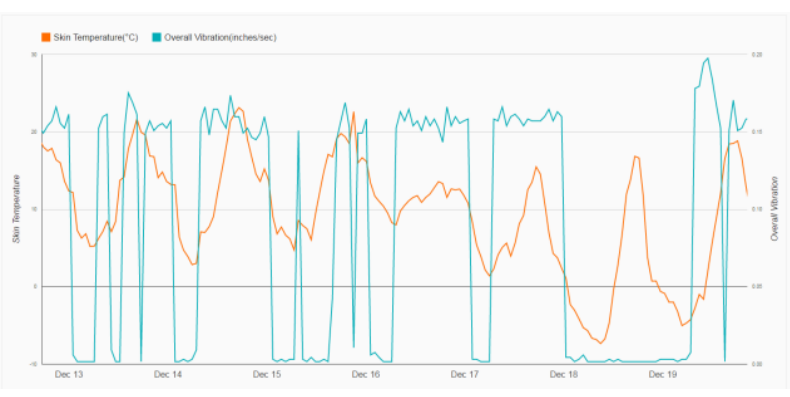

Fig. 13. Motor skin temperature and vibrations.

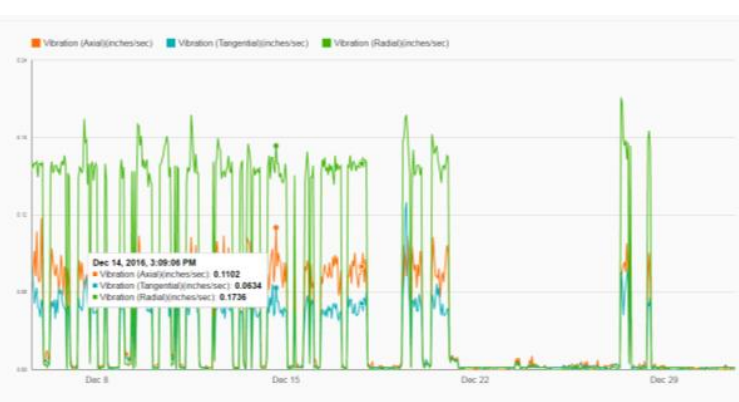

Fig. 14. Axial, tangential and radial vibrations.

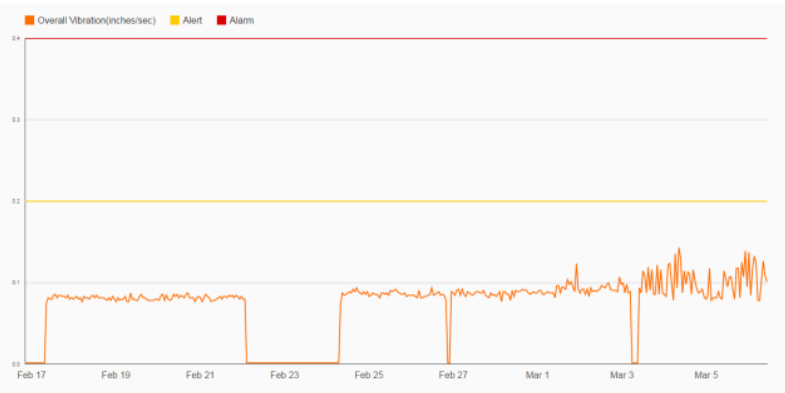

Fig. 15. Motor vibrations with alert and alarm values.

Further information including the overview of available functions released step by step is available at: https://smartsensor.desk.com/.

\section{Variable Speed Drives in a Digital World}

Thanks to their construction, the variable speed drives have not big problems when it comes to digitalization. Even today they are optionally equipped with elements for standardized communication with supervisory control system. Within the next subsections three interesting new services will be introduced that further expand these possibilities even further.

\section{1) Drivebase}

Drivebase is an $\mathrm{ABB}$ tool that allows the customers to register their purchased variable speed drive easily and enable them - using mobile phone and QR code - to quickly obtain service contacts, links to manuals, and possibility to analyze error messages and to identify at what stage of the life cycle the variable speed drive is. Its communication is cloud-based and off-line.

\section{2) Remote Condition Monitoring Service}

Remote Condition Monitoring of variable speed drives is a service product that enables remote and on-line monitoring of the status of the variable speed drive and its operation. Current data and reports are available on myabb.com. ABB experts evaluate the monitored data and are able to predict failures and recommend preventive measures. Information about diagnosed failures, exceeded set limits or related alerts are sent by e-mail.

\section{3) Drivetune}

Within IoSTP and in compliance with the trend to "drive data in one's own pocket", $\mathrm{ABB}$ has developed a unique smartphone application enabling to tune the variable speed drive from a mobile phone, again via Bluetooth (Fig. 16 and Fig. 17). The application can be 
simply downloaded to the mobile phone and used as a drive control panel. After downloading, a DEMO is available to users giving them opportunity to learn about application possibilities. Drivetune makes it possible to connect to the drive, enter data necessary to start up the drive, to troubleshoot, perform the basic parameterization and others, all while ensuring cyber security. The advantage of Drivetune is that it eliminates the necessity to keep the maximum 3-meter distance (cable) between the panel and drive. With mobile the distance can be up to 70 meters from the variable speed drive with sensor (in case there are some obstacles, the distance is proportionally shortened) - i.e. directly next to the driven technology and to set up precisely required parameters. Data can be also sent to the cloud where ABB service technicians can access them and based on consultations identify the necessary tuning or measures. When presented on Amper 2016 trade fair the application was granted Golden Amper 2016 award.

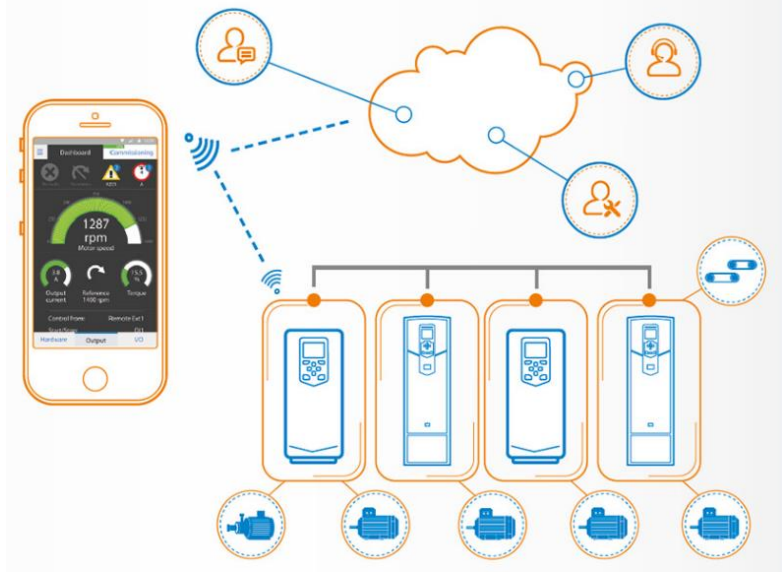

Fig. 16. Controlling the drive using a mobile phone.

\section{CONCLUSION}

Digitization takes place in a wide range of industrial segments such as electronics, electrical engineering, construction and production of machinery and equipment, manufacture of tools, automotive, energy, chemical and pharmaceutical production, metallurgy and steel, information technology and telecommunications, industrial automation, radio communication, as well as service and maintenance, banking, financial and marketing services, sales activities, consulting services, advertising activities, software development, agriculture, environment, health, nutrition and others. It thus can be said that the goal of Industry 4.0 is a full digital interconnection of all levels from product development to logistics. To achieve this goal, radical changes and forethoughtful investment planning in both large and small businesses will be necessary.

\section{REFERENCES}

[1] Internal materials of $A B B$

[2] Website of Ministry of Industry and Trade https://www.mpo.cz/en/industry/industry-4-0/initiative-industry-4-0approved-by-the-czech-government--177195/
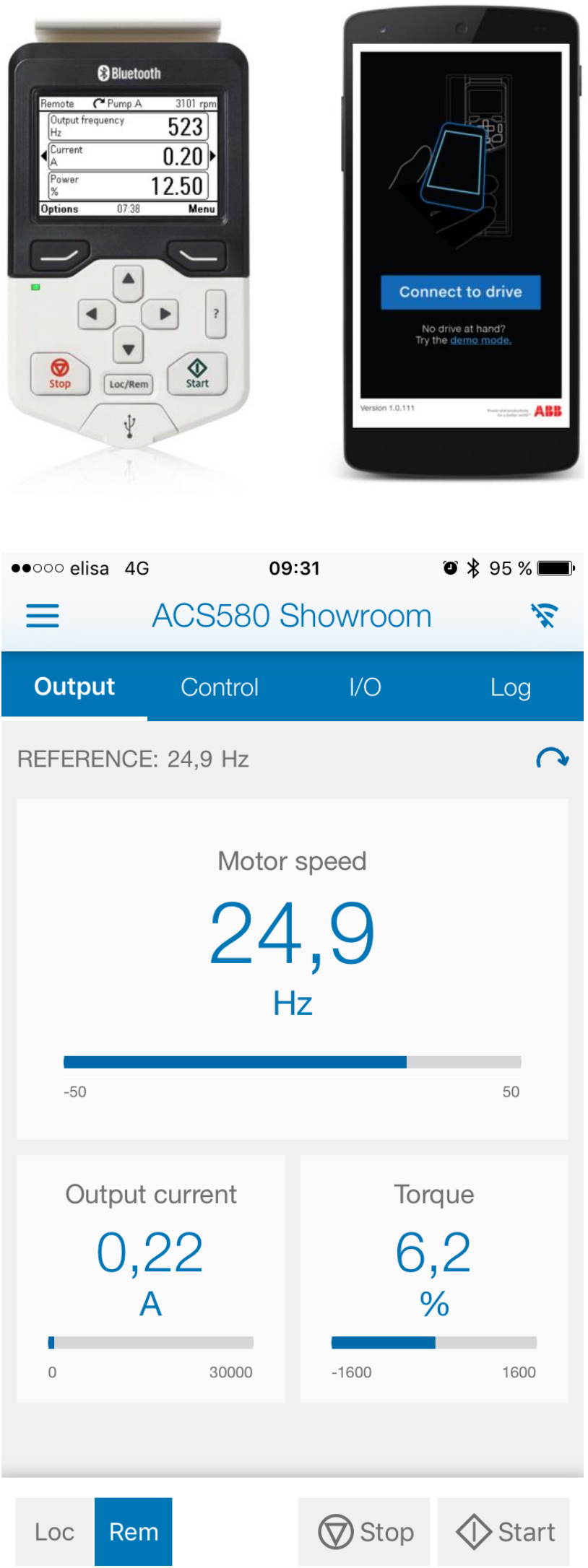

Fig. 17. Control panel and mobile phone communication. 